\title{
Effects of Teachers Level of Education and Experience on Teacher-Child Interactions in Early Childhood Institutions
}

\author{
Nana Yaa Nyarko ${ }^{1}$, Hillar Addo ${ }^{2}$ \\ ${ }^{1}$ Department of Family and Consumer Science, University of Ghana, Legon, Ghana \\ ${ }^{2}$ Department of Information Technology, University of Professional Studies, Accra, Ghana \\ Email: ynyarko@ug.edu.gh
}

Received September $5^{\text {th }}$, 2013; revised October $7^{\text {th }}$, 2013; accepted November $12^{\text {th }}$, 2013

Copyright (C) 2013 Nana Yaa Nyarko, Hillar Addo. This is an open access article distributed under the Creative Commons Attribution License, which permits unrestricted use, distribution, and reproduction in any medium, provided the original work is properly cited.

\begin{abstract}
Early childhood care and development (ECCD) in Ghana have received attention in the last decade. To ensure quality of instruction and build capacity of early childhood teachers and caregivers, the National Nursery Teachers' Training Centre was set up by the government to offer specialized training in nursery education for teachers and nursery attendants. Universities and the Colleges of Education have been mandated to train teachers for early childhood education. This study therefore sought to find out the effects of level of education and years of experience of teachers on their interactions with children (3 - 5) in earlychildhood institutions in Ghana using the Caregiver Child Interaction Scale $(r=0.77)$. The sample $(N=$ 103; Female 99\%): made up of teachers from thirty-one preschools in the Greater Accra Region of Ghana were observed during their normal classroom routine. There appeared not to be any statistically significant difference between the teachers' level of education and years of experience on the interaction scores.
\end{abstract}

Keywords: Teacher-Child Interactions; Years of Experience; Teacher Education

\section{Introduction}

It has been just a little over a decade since the Government of Ghana put together the early childhood care and education policy to cater for the needs of working mothers and their infants. Kindergarten education (for four year olds) was not the part of the formal educational system; it was introduced as a result of recommendations made by the President's Committee on Review of Education Reforms (Ministry of Education, AnamoahMensah Report, 2002). The Early Childhood Care and Development (ECCD) Policy of Ghana provide the broad policy goal which is to promote the survival, growth and development of all children (0 - 8 years) in Ghana and to ensure improved standard of living and enhance quality of life for families in Ghana (ECCD, 2002). The policy also focuses on building the capacity of ECCD practitioners and quality of instructions among its goals and objectives.

The United Nations Educational, Scientific and Cultural Organization (UNESCO) International Bureau of Education (IBE) country profile report on Early Childhood Care and Education programmes in Ghana (2006) revealed that only $22.2 \%$ of 22,014 early childhood teachers had received training. The quality of instruction has become of great concern due to the rapid expansion of preschool services. National policy (ECCD, 2002) in Ghana aims to address current problems of access and quality in early childhood education by promoting the professional identity, prestige and respect for early childhood educators. The Ghanaian government mandated teacher education institutions such as Colleges of education, Universities of Education i.e. Cape Coast and Winneba were expanded to maximize use of their training facilities, as well as prepare researchers and early childhood leaders who can assume critical roles in advancing early childhood education throughout the nation. National Nursery Teachers' Training Centre (NNTTC) was also set up by government to enable training of nursery teachers and attendants over three months duration.

Ofosu-Appiah (2009) opines that Ghana lacks teachers who have specialized in preschool or early childhood education. The Director of Basic Education, Ghana Education Services, is reported to have said that participation at kindergartens and early childhood programmes as a whole have increased since 2007 (Sivan, 2010). The universities and colleges of education until recently did not have programmes in early childhood education. In effect there are no real professionals in that area, "what we have been doing over the years is just trial and error" (OfosuAppiah, 2009). Factors known to influence quality of teacher child interactions have been teacher education (Berk, 1985; Ruopp, Travers, Glantz, \& Coelen, 1979; Whitebook, Howes, \& Phillips, 1990), and a specialization in child development (Arnett, 1989).

\section{Statement of Problem}

There is a shortage in supply of specialized early childhood education teachers to meet the current demand but participation in early childhood programmes in Ghana has increased. Quality of instruction in ECD programmes are compromised as the professionals responsible lack the needed training. This study therefore sought to find out if indeed teachers' interactions with children in their care would be affected by their level of educa- 
tion and or years of experience.

\section{Objectives of Study}

1) To ascertain the effect of the level of education on the teachers interactions with children in their care.

2) To find out the effect of years of experience on teachers interactions with children in their care.

\section{Hypotheses}

The study proposes the testing of the following hypotheses:

$\mathrm{Ho}^{1}$ : The interaction scores of Teachers with a post secondary education will not be statistically different from teachers with no post secondary education.

$\mathrm{Ho}^{2}$ : The interaction scores of Teachers with longer years of experience will not be statistically different from teachers with little or no years of experience.

\section{Methodology}

The study was a descriptive survey. Hundred and three (103) teachers who taught in early childhood institutions in the Greater Accra Region of Ghana were purposively sampled for the study. A pilot study was undertaken on five (5) preschool teachers (not part of final analysis) to ensure content validity. The calculated Cronbach's alpha is 0.77 which is above 0.50 and therefore considered more than appropriate (Nunnally \& Berstein, 1994) for the study. Observations were conducted by the researchers and two trained research assistants. The chi square statistic was used to test the hypotheses.

\section{Sample}

One hundred and three teachers from various schools in the Greater Accra Region of Ghana with a focus on early childhood education were sampled to form part of the study. Sampled teachers were those who taught ages 3 - 5, i.e. nursery, kindergarten 1 and kindergarten 2 .

\section{Procedure}

Informed consent was obtained from heads of institutions and teachers who were willing to participate in the study before a date was scheduled for the observation. Observation of a teacher in a classroom took an average of four hours. All heads of schools and teachers were assured confidentiality in that the data would be used for research purposes alone. The observation guidelines set in the Caregiver Child Interaction Scale scoring manual was followed strictly. To minimize distracting children, researcher and assistants dressed in pale colours and sat unobtrusively in the class. The teachers were revisited to ascertain if the observation had any bad effects on the class. Ethical clearance was obtained from the Noguchi Memorial Institute for Medical Research Review Board.

\section{Instrument} 2010

The Caregiver-Child Interaction Scale (CCIS) -Barbara Carl

It is a 14 item measurement tool used to assess teacher child interaction. The 14 items are organized into three domains (Emotional-Tone of Voice, Acceptance/Respect for Children, Enjoys and Appreciates Children, Expectations for Children. Cognitive/physical-Health and Safety, Routine/times Spent,
Physical Attention, Discipline, Language Development, Learning Opportunities, Involvement with Children's Activities. And Connections with a wider world-Arrival, Promotion of prosocial Behaviour/social Emotional Learning and Relationship with Families. The CCIS is a tool that can be used to improve quality child care. Each item is presented as a 7-point scale with detailed criteria at four anchor points: 1 (inadequate), 3 (minimal), 5 (good), and 7 (excellent). Numerous indicators comprise each CCIS item. Each of these indicators operationally defines specific actions that comprise a score. Either the behaviour is present or it is not. This method removes much of the subjectivity in scoring. It reports an internal consistency of 0.94 .

\section{Data Analysis}

Data was coded and analysed using the Statistical Package for the Social Sciences. Means and standard deviations for the population were derived. The Chi square statistic was used to test hypotheses on level of education and years of experience.

\section{Results}

\section{Age, Level of Education and Experience of Study Participants}

Table 1 documents the background characteristics of the study participants as follows. The mean age $(n=97)$ reported is 36 and standard deviation of 11 . About $69 \%$ of teachers were young adults (i.e. 20 - 40). About $50 \%$ of the sample had Secondary education as their highest level of education. Trained (diploma and degree holders) teachers formed only 32\% con-

Table 1.

Background characteristics of study participants $(\mathrm{N}=103)$.

\begin{tabular}{cc}
\hline Characteristics & $\mathbf{n}(\mathbf{\%})$ \\
\hline Caregiver age (years) (n = 97) (Mean \pm SD) & $36 \pm 11$ \\
$31-40$ & $35(36.1)$ \\
$41-50$ & $32(32.98)$ \\
$51-71$ & $21(21.65)$ \\
Educational level (n = 101) & $9(9.28)$ \\
JHS & \\
SHS/O\&A Level & $7(6.9)$ \\
Certificate/NNTTC & $52(51.5)$ \\
Diploma/Training college & $8(7.9)$ \\
Degree & $18(17.8)$ \\
Number of years of experience in child care $(\mathbf{n}=\mathbf{1 0 3})$ & $15(14.9)$ \\
$<1$ & $2(1.9)$ \\
$1-3$ & $21(20.4)$ \\
$4-6$ & $24(23.3)$ \\
$7-10$ & $18(17.5)$ \\
$11-15$ & $15(14.6)$ \\
$16-20$ & $10(9.7)$ \\
$>20$ & $13(12.6)$ \\
\hline
\end{tabular}


firming UNESCO International Bureau of Education country profile report on Early Childhood Care and Education programmes in Ghana (2006) and Ofosu-Appiah, (2009) that Ghana lacked specialized early childhood teachers. Teachers' years of experience with childcare varied from 1 - 20 years. This could probably be due to an increase in the participation in kindergarten and early childhood programmes as a whole (Sivan, 2010). Hence creating job opportunities for the youth (young adults) in Ghana.

\section{Hypothesis 1}

Teachers' educational level did not have any effect on their interactions (Table 2). The only domain likely to have been influenced is Connections with a wider world at $(p=0.07)$. Teachers had a way of helping children understand acceptable behaviour and norms, however statistically this could not be proven.

\section{Hypothesis 2}

Years of experience (Table 3 ) though not statistically significant could likely influence the emotional domain $(p=0.08)$. Over time teachers may have learnt not to react overly by shouting around children as it brings no positive results. In an interview with one teacher she said "if you shout on a child too

Table 2.

Teachers Educational level Against Interaction Scores on CCIS Domains.

\begin{tabular}{|c|c|c|c|c|c|c|c|c|}
\hline \multirow{2}{*}{ Domain } & \multirow{2}{*}{ Classification } & \multicolumn{6}{|c|}{ Educational level n (\%) } & \multirow{2}{*}{${ }^{\#} p$-value } \\
\hline & & JHS & SHS/O\&A level & Certificate/NNTTC & Diploma/training college & Degree & Masters & \\
\hline \multirow{3}{*}{ EMOT } & Low care & $2(2.1)$ & $9(9.4)$ & $2(2.1)$ & $3(3.1)$ & $5(5.2)$ & $0(0.0)$ & \multirow{3}{*}{0.80} \\
\hline & Minimal care & $4(4.2)$ & $33(34.4)$ & $4(4.2)$ & $12(12.5)$ & $6(6.2)$ & $1(1.0)$ & \\
\hline & Excellent care & $0(0.0)$ & $10(10.4)$ & $0(0.0)$ & $3(3.1)$ & $2(2.1)$ & $0(0.0)$ & \\
\hline \multirow{3}{*}{$\mathrm{COPH}$} & Low care & $3(3.1)$ & $24(25.0)$ & $2(2.1)$ & $7(7.3)$ & $5(5.2)$ & $0(0.0)$ & \multirow{3}{*}{0.97} \\
\hline & Minimal care & $3(3.1)$ & $25(26.0)$ & $4(4.2)$ & $9(9.4)$ & $8(8.3)$ & $1(1.0)$ & \\
\hline & Excellent care & $0(0.0)$ & $3(3.1)$ & $0(0.0)$ & $2(2.1)$ & $0(0.0)$ & $0(0.0)$ & \\
\hline \multirow{3}{*}{ COWW } & Low care & $4(4.2)$ & 31 (32.3) & $1(1.0)$ & $9(9.4)$ & 11(11.5) & $1(1.5)$ & \multirow{3}{*}{0.07} \\
\hline & Minimal care & $2(2.1)$ & $20(20.8)$ & $3(3.1)$ & $8(8.3)$ & $2(2.1)$ & $0(0.0)$ & \\
\hline & Excellent care & $0(0.0)$ & $1(1.0)$ & $2(2.1)$ & $1(1.0)$ & $0(0.0)$ & $0(0.0)$ & \\
\hline \multirow{3}{*}{ TOTA } & Low care & $2(2.1)$ & 13 (13.5) & $1(1.0)$ & $2(2.1)$ & $5(5.2)$ & $0(0.0)$ & \multirow{3}{*}{0.53} \\
\hline & Minimal care & $4(4.2)$ & 39 (40.6) & $5(5.2)$ & $16(16.7)$ & $8(8.3)$ & $1(1.0)$ & \\
\hline & Excellent care & & & & & & & \\
\hline
\end{tabular}

EMOT = Emotional domain; COPH = Cognitive/Physical education; COWW = Connection with a wider world; TOTA = Total caregiver domain score; ${ }^{\#}$ No statistically significant differences were observed at $p<0.05$ (Fisher's exact test).

Table 3.

Teachers years of experience against interaction scores on the CCIS domains.

\begin{tabular}{|c|c|c|c|c|c|c|c|c|c|}
\hline \multirow{2}{*}{ Domain } & \multirow{2}{*}{ Classification } & \multicolumn{3}{|c|}{ Years of experience n (\%) } & \multirow[t]{2}{*}{${ }^{\#} \boldsymbol{p}$-value } & \multicolumn{3}{|c|}{ Years of experience with this age level $n(\%)$} & \multirow{2}{*}{$\# p$-value } \\
\hline & & $0-10$ & $11-20$ & $>20$ & & $0-10$ & $11-20$ & $>20$ & \\
\hline \multirow{3}{*}{ EMOT } & Low care & $17(17.0)$ & $2(2.0)$ & $3(3.0)$ & & $21(21.0)$ & $0(0)$ & $1(1.0)$ & \\
\hline & Minimal care & 39 (39.0) & $15(15.0)$ & $8(8.0)$ & 0.08 & $55(55.0)$ & $7(7.0)$ & $0(0)$ & 0.10 \\
\hline & Excellent care & $7(7.1)$ & $8(18.0)$ & $1(1.0)$ & & $11(11.0)$ & $5(5.0)$ & $0(0)$ & \\
\hline \multirow{3}{*}{ COPH } & Low care & $31(31.0)$ & $7(7.0)$ & $5(5.0)$ & & $38(38.0)$ & $3(3.0)$ & $1(1.0)$ & \\
\hline & Minimal care & $29(29.0)$ & $16(16.0)$ & $7(7.0)$ & 0.37 & $45(45.0)$ & $8(8.0)$ & $0(0)$ & 0.32 \\
\hline & Excellent care & $3(3.0)$ & $2(2.0)$ & $0(0)$ & & $4(4.0)$ & $1(1.0)$ & $0(0)$ & \\
\hline \multirow{3}{*}{ coww } & Low care & $36(36.0)$ & $13(13.0)$ & $10(10.0)$ & & $50(50.0)$ & $8(8.0)$ & $1(1.0)$ & \\
\hline & Minimal care & $25(25.0)$ & $10(10.0)$ & $2(2.0)$ & 0.34 & 33 (33.0) & $4(4.0)$ & $0(0)$ & 1.00 \\
\hline & Excellent care & $2(2.0)$ & $2(2.0)$ & $0(0.0)$ & & $4(4.0)$ & $0(0)$ & $0(0)$ & \\
\hline \multirow{3}{*}{ TOTA } & Low care & $19(19.0)$ & $2(2.0)$ & $3(3.0)$ & & $23(23.0)$ & $0(0)$ & $1(1.0)$ & \\
\hline & Minimal care & $44(44.0)$ & 23 (23.0) & $9(9.0)$ & 0.08 & $64(64.0)$ & $12(12.0)$ & $0(0.0)$ & 0.17 \\
\hline & Excellent care & - & - & - & & - & - & - & \\
\hline
\end{tabular}

EMOT = Emotional domain; COPH = Cognitive/Physical education; COWW = Connection with a wider world; TOTA = Total caregiver domain score; ${ }^{\#}$ No statistically significant differences were observed at $\mathrm{p}<0.05$ (Fisher's exact test). 
much he or she becomes timid”.

\section{Discussion}

The present study examined relationships between the teachers' interaction scores on developmental domains with their level of education (Table 2) and years of experience (Table 3). There were no significant differences between level of education and years of experience and the teachers' interaction scores hence both hypotheses were retained. Teachers observed were predominantly females (99\%) and perhaps had been socialized to become 'nurturing' where older siblings were made to care for younger ones. Teachers' Sunday school experiences were also not assessed. These experiences could have implications in future research but was not investigated as part of teachers' total years of care giving experience.

Teacher education (Berk, 1985; Ruopp, Travers, Glantz, \& Coelen, 1979; Whitebook, Howes, \& Phillips, 1990), and a specialization in child development (Arnett, 1989) are factors known to influence quality of teacher child interactions, the present study did not find any correlations between them. Even though it appeared there were no statistically significant differences the study had enough power to detect medium to small effect sizes. Cohen (1992), records that sample sizes of 64 and 26 was needed to determine medium to small effect sizes respectively at 0.05 level of significance. This study had a sample size of 103 about twice the size needed for medium to small effect sizes.

\section{Conclusion}

With early childhood care and development programmes still evolving in Ghana, one would have expected that there will be a clear difference between the few trained and experienced teachers and the untrained inexperienced ones. This was not so in this study. Is it likely that generally the way of socialization informally prepared teachers as care givers? Further qualitative studies are recommended.

\section{REFERENCES}

Arnett, J. (1989). Caregivers in day-care centers: Does training matter? Journal of Applied Developmental Psychology, 10, 541-552. http://dx.doi.org/10.1016/0193-3973(89)90026-9

Berk, L. (1985). Relationship of caregiver education to child-oriented attitudes, job satisfaction, and behaviors toward children. Child Care Quarterly, 14, 103-129. http://dx.doi.org/10.1007/BF01113405

Carl, B. (2010). The child caregiver interaction scale, revised edition. Poster session presented at the Capital Area Association for the Education of Young Children, Harrisburg, PA.

Cohen, J. (1992). Power primer: Quantitative methods in psychology. Psychological Bulletin, 12, 155-159. http://dx.doi.org/10.1037/0033-2909.112.1.155

Ministry of Education (2002). Report of the President's Committee on Review of Education Reforms in Ghana (Anamuah-Mensah Report), Ministry of Education, Accra.

Nunnally, J. C., \& Bernstein, I. H. (1994). Psychometric theory (3rd ed.). New York: McGraw-Hill.

Ofosu-Appiah, B. (2009). Educational reforms should start from preschool.

Republic of Ghana Ministry of Women and Children's Affairs (2002). Early childhood care and development policy. http://mowacghana.net/files/eccdp.pdf

Ruopp, R., Travers, J., Glantz, F., \& Coelen, C. (1979). Children at the center: Final Report of the National Day Care Study. Cambridge, MA: Abt Associates.

UNESCO International Bureau of Education (2006). Ghana: Early childhood care and education programmes. http://unesdoc.unesco.org/images/0014/001471/147192e.pdf

Ward, S. L., \& Wilcox-Herzog, A. (2004). Measuring teachers' perceived interactions with children: A tool for assessing beliefs and intentions. Early Childhood Research and Practice, 6, 2.

Whitebook, M., Howes, C., \& Phillips, D. (1990). Who Cares? Child Care Teachers and the Quality of Care in America. Final Report of the National Child Care Staffing Study. Oakland, CA: Child Care Employee Project.

Sivan, P. (2010). Improving the Quality of Early Childhood Programmes Offered to Children of Ghana: ECD QUALITY FRAMEWORK A REPORT Submitted to: UNICEF Ghana. 